Gut, 1973, 14, 319-323

\title{
The physical state of bile acids in the diarrhoeal stool of ileal dysfunction
}

\author{
J. M. FINDLAY, M. A. EASTWOOD, AND W. D. MITCHELL \\ From the Wolfson Gastro-intestinal Laboratory Gastro-intestinal Unit, Western General Hospital and \\ University of Edinburgh, Edinburgh
}

SUMmARY A method is described for the separation of a diarrhoeal stool into solid and liquid phases. The seven patients studied had varying degrees of ileal resection. Faecal bile acids were measured in supernatant and pellet. Freeze-dried pellet of the patients had significantly higher bile acid content than freeze-dried faeces of the eight controls (patients mean $=55.8 \mathrm{mg}$ bile acids/ $\mathrm{g}$ freeze-dried faeces; normals $=8.3 \mathrm{mg}$ bile acids $/ \mathrm{g}$ freeze-dried faeces; $\mathrm{P}<0.005$ ). The presence of bile acids in the supernatant of these patients is discussed with regard to the binding capacity of the dietary residue in the colon. The faecal excretion of bile acids throughout the day in three patients was studied using the centrifugation method.

It is easy to recognize a diarrhoeal stool on inspection. It is less easy to arrive at a method of measuring the changes in the stool which are so characteristic. The stool is no longer formed but contains an additional liquid component.

In the diarrhoea of ileal dysfunction there is an increased loss of water (Woodbury and Kern, 1971) and bile acids in the stool (Hofmann and Poley, 1969).

It is known that in the normal stool bile acids are strongly associated with the solid material in the stool (Norman, 1964).

Information is not available as to the quantities of bile acids associated with the solid component of the stool in the diarrhoeal situation. This paper describes a centrifugation method which separates the free water of the diarrhoeal stool from a pellet which has a water content similar to normal stool. This enables estimates to be made of water and bile acid distribution in these abnormal faeces.

To show that any difference in bile acid content of supernatant and pellet is not due to unequal distribution between the liquid component of the pellet and supernatant, it is necessary to show that the liquid component of the pellet is essentially the same as the liquid component of the supernatant. A suitable indicator of this is the electrolyte concentration of both phases.

Received for publication 8 February 1973.

\section{Materials and Methods}

\section{Patients studied}

Clinical details are given in table I. The length of resection in patient 6 is not known but the intestine removed consisted of multiple coils of ileum heavily infiltrated with Crohn's disease. All seven patients had ileal resections; six had varying lengths of colon or caecum removed.

No subjects were treated with bile acid-sequestrating agents during the time of study. The eight control subjects were members of staff and had no clinical evidence of any gastrointestinal disease.

\section{CENTRIFUGATION OF FAECES}

Individual stools were collected for three to five days in disposable plastic bags according to the description of Hinton, Lennard-Jones, and Young (1969). Completeness of collection was indicated by more than $80 \%$ recovery of radioopaque markers (Hinton et al, 1969) which were given at the onset of the collection for coincidental transit time studies. All the patients were instructed to collect faeces free from urine. Initially urea estimations of supernatant were used to exclude the presence of urine (Varley, 1962a). Subsequently the liberation of ammonia during faecal bile acid analysis indicated a urine-contaminated stool. An entire collection of stool from one patient was excluded from this study on this basis. 




Table I Clinical data

The samples were kept at $-20^{\circ} \mathrm{C}$ until analysed. When required the samples were thawed and homogenized. No water was added except to the specimens of the normals. Aliquots of homogenates were then centrifuged at $14000 \mathrm{~g}$ for one hour at $10^{\circ} \mathrm{C}$ in an MSE Mistral 2L centrifuge with high speed head attachment. The supernatant and pellet were freeze dried and the bile acids measured by the method of Evrard and Janssen (1968). A slight modification was the use of a $3 \%$ OV-17 Gas Chrom $\mathrm{Q}$ column at $275^{\circ} \mathrm{C}$ isothermally. Recoveries of added cholic acid, chenodeoxycholic acid, deoxycholic acid, and lithocholic acid to faecal samples were $(\mathrm{n}=4) 98 \%, 98 \%, 100 \%$, and $91 \%$ respectively. The coefficient of variation of duplicate analysis ( $\mathrm{n}=16$ ) using a standard mixture was monoketo acids $7 \cdot 7 \%$, diketo acids $5 \cdot 6 \%$, and triketo acids $8.5 \%$.

In three patients faecal electrolytes were measured in supernatant and pellet using an AutoAnalyzer method. Pellet electrolytes were analysed after digestion in Analar concentrated nitric acid.

\section{Results}

CENTRIFUGATION: EVALUATION OF METHOD Duplicate samples of faecal homogenate were centrifuged at various speeds for varying times. The results are expressed as pellet percentage of total weight. The results are shown in figure 1 . Centrifugation at low speeds for a long time, eg, one hour, did not give a satisfactory separation whereas centrifugation at $14000 \mathrm{~g}$ for one hour gave a good

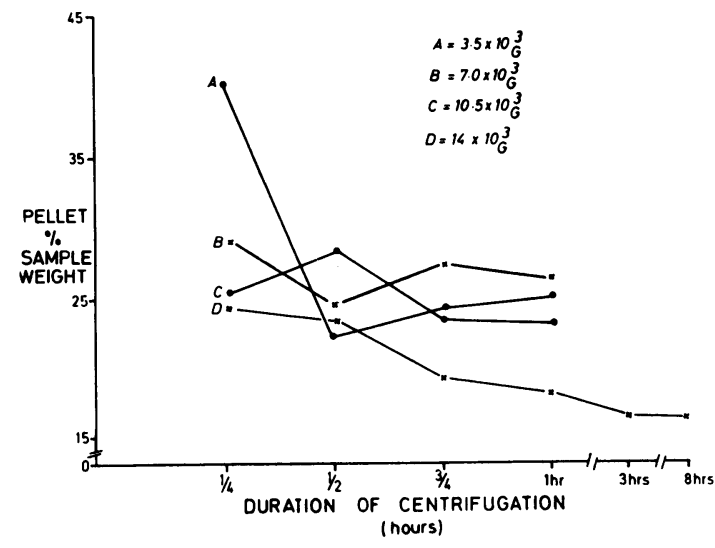

Fig 1 The effect of time and speed on the separation of a diarrhoeal stool into supernatant and pellet by centrifugation

$\frac{\text { Pellet weight }}{\text { Sample weight }} \times 100=$ pellet $\%$ sample weight

separation into a clear supernatant and pellet. There was very little change when centrifugation at $14000 \mathrm{~g}$ was continued for as long as eight hours ( $2 \%$ more supernatant after eight hours compared with one hour). Higher speeds have not been examined in this study.

To determine whether storage at $-20^{\circ} \mathrm{C}$ for 72 hours could affect the bile acid content of the supernatant, a freshly collected sample was homogenized. An aliquot was stored at $-20^{\circ} \mathrm{C}$ and another 
aliquot from the same sample was centrifuged immediately in duplicate at $14000 \mathrm{~g}$ for one hour. After 72 hours at $-20^{\circ} \mathrm{C}$ the first aliquot was thawed, remixed, and then centrifuged in duplicate at $14000 \mathrm{~g}$ for one hour. The bile acid content of the supernatant in the two separately treated aliquots showed no significant difference (freshly collected $=0.87 \mathrm{mg} / \mathrm{g}$, after storage at $-20^{\circ} \mathrm{C}=0.81$ $\mathrm{mg} / \mathrm{g}$ ).

To investigate whether centrifugation at $14000 \mathrm{~g}$ for different periods of time affected the bile acid content of the supernatant a faecal sample was centrifuged for five minutes, 20 minutes, and one hour at $14000 \mathrm{~g}$. An aliquot of the clear supernatant was taken with a Pasteur pipette after each time interval and the bile acid content was measured. The change of $11 \%$ in bile acid content which occurred after 20 minutes and 60 minutes $(0.73$ $\mathrm{mg}$ and $0.81 \mathrm{mg} / \mathrm{g}$ respectively) is within the range of experimental error of the method used (diketo acids $=5.6 \%$; triketo acids $=8.5 \%$ ). Centrifugation for only five minutes compared with centrifugation for one hour $(1.08 \mathrm{mg} / \mathrm{g}$ and $0.81 \mathrm{mg} / \mathrm{g}$ of freeze-dried supernatant respectively) showed an increase of $25 \%$. This is beyond the range attributable to experimental error and may be due to incomplete separation into pellet and supernatant after five minutes, the volume of supernatant obtained after five minutes being much less than that obtained after 20 minutes and 60 minutes.

CENTRIFUGATION OF FAECES

Table II compares the effect of centrifuging the patients' stools with those of the normals. In patients 3,4 , and 5 faecal samples were pooled to produce daily collections. The results are expressed in terms of the pellet as a percentage of the total stool weight. The patients' faeces contained from 35 to $62 \%$ pellet. After centrifugation for one hour at $14000 \mathrm{~g}$ and $10^{\circ} \mathrm{C}$ the stool separated into three recognizable layers: a supernatant, a fatty layer, and a pellet. The fatty layer adhered to the pellet and throughout the study was considered as part of the pellet. In normal subjects no separation into two phases occurred on centrifugation. The normal stool was therefore regarded as comprising $100 \%$ pellet.

\section{FAECAL BILE ACID ANALYSIS}

Table II shows the amount of bile acids in the freezedried pellet, expressed as $\mathrm{mg} / \mathrm{g}$, obtained from the faeces of patients with diarrhoea and the control subjects. The bile acids $(\mathrm{mg} / \mathrm{g}$ supernatant) in the supernatant obtained by centrifugation of the diarrhoeal stool is also given in table II. There is a significantly larger amount of bile acids associated with the freeze-dried pellet in the patients with diarrhoea than in the control subjects (mean bile acid content of freeze-dried pellet: patients $=55.8 \mathrm{mg} / \mathrm{g}$, controls $=8.3 \mathrm{mg} / \mathrm{g} ; \mathrm{P}<0.005$ ). These patients with ileal resection also had appreciable amounts of bile acids in the supernatant $(0 \cdot 3-7 \cdot 3 \mathrm{mg} / \mathrm{g}$, ie, 0.7-18 $\mathrm{mM})$. The control subjects had no supernatant.

FAECAL ELECTROLYTES

The results are given in table III as milliequivalents electrolyte/100 g supernatant or pellet. It can be

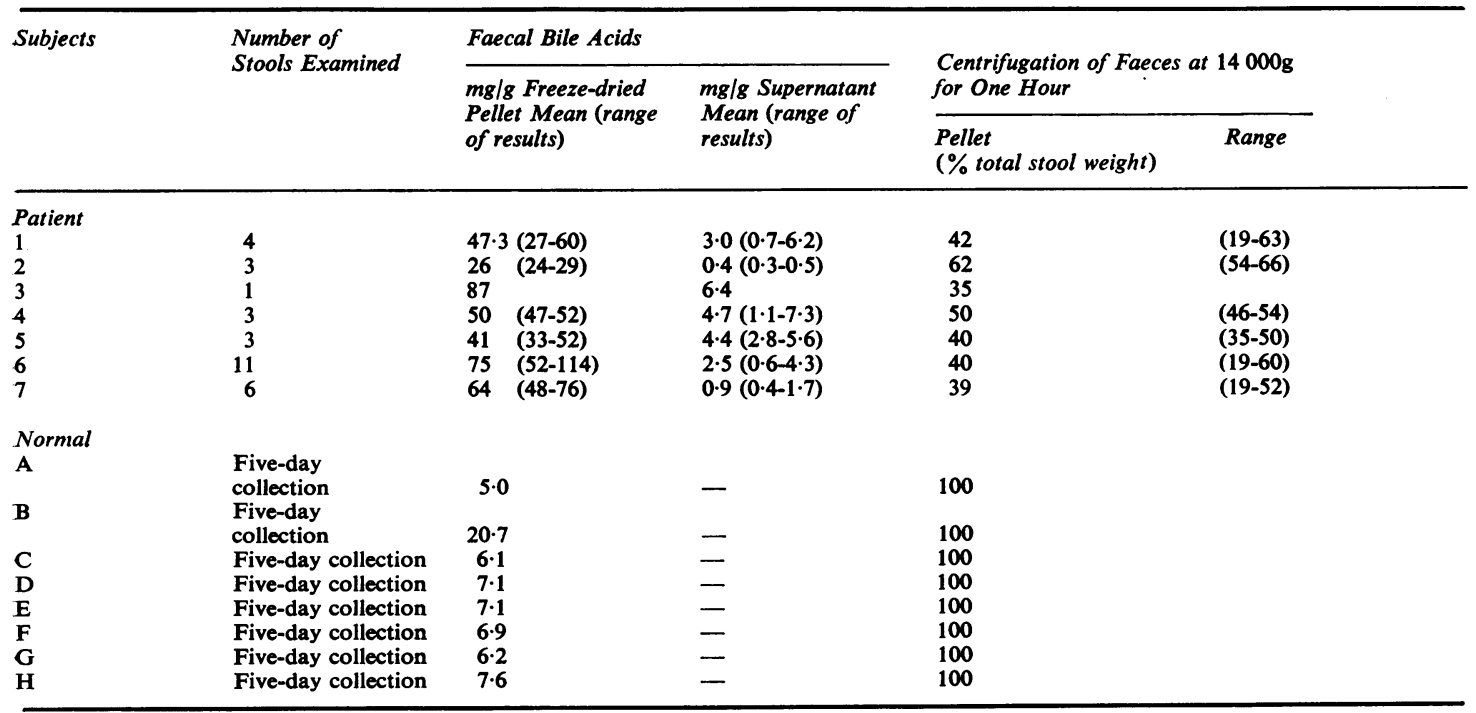

Table II Freeze-dried material 


\begin{tabular}{|c|c|c|c|c|c|c|}
\hline \multirow[t]{2}{*}{ Patient } & \multicolumn{3}{|l|}{ Pellet } & \multicolumn{3}{|c|}{ Supernatant } \\
\hline & $\mathrm{Na}^{+}$ & $K^{+}$ & $\mathrm{Cl}^{-}$ & $\mathrm{Na}^{+}$ & $\boldsymbol{K}^{+}$ & $\mathrm{Cl}^{-}$ \\
\hline $\begin{array}{l}1 \\
4\end{array}$ & $\begin{array}{l}5.0 \\
7.0 \\
6.0 \\
7.0 \\
7.0 \\
6.0 \\
7.0\end{array}$ & $\begin{array}{l}5.0 \\
4 \cdot 0 \\
4 \cdot 0 \\
4 \cdot 0 \\
4.0 \\
5.0 \\
5.0\end{array}$ & $\begin{array}{l}2.0 \\
4 \cdot 0 \\
3.0 \\
4 \cdot 0 \\
4 \cdot 0 \\
2.0 \\
3.0\end{array}$ & $\begin{array}{l}5.0 \\
7.0 \\
6.0 \\
7.0 \\
7.0 \\
6.0 \\
7.0\end{array}$ & $\begin{array}{l}5 \cdot 0 \\
4 \cdot 0 \\
4 \cdot 0 \\
4 \cdot 0 \\
4 \cdot 0 \\
5 \cdot 0 \\
5 \cdot 0\end{array}$ & $\begin{array}{l}2.0 \\
4 \cdot 0 \\
3 \cdot 0 \\
4 \cdot 0 \\
4 \cdot 0 \\
2.0 \\
3.0\end{array}$ \\
\hline
\end{tabular}

Table III Faecal electrolytes (m-equiv/100 g)

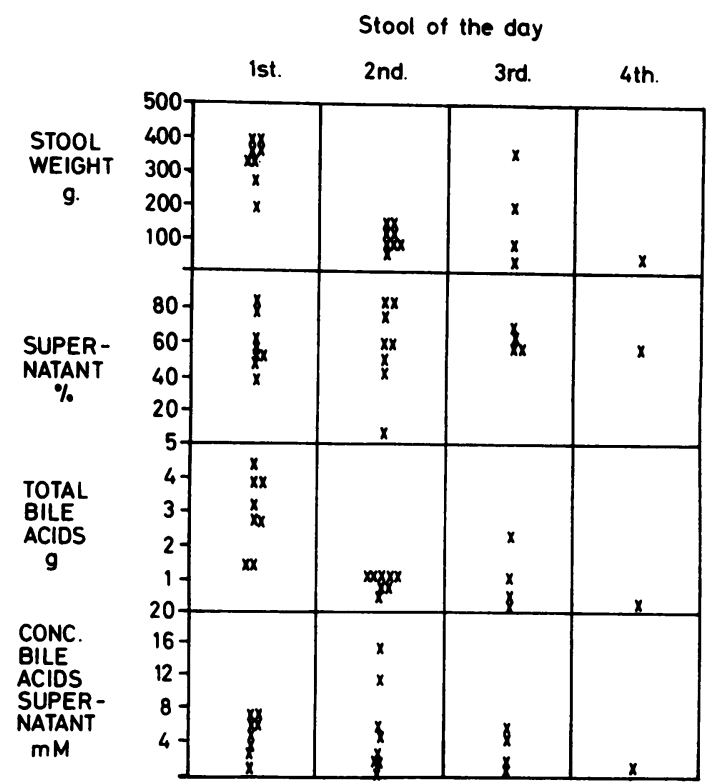

Fig. 2 The distribution throughout the day in three patients $(1,6$, and 7$)$ of total faecal weight, supernatant, total faecal bile acids and concentration of bile acids in the supernatant

seen that the electrolytes are uniformly distributed between pellet water and supernatant water which suggests that the supernatant water and pellet water are in equilibrium.

FAECAL FAT

Five of the seven patients had faecal fat (Varley, 1962b) values greater than the normally accepted level (table I).

WATER CONTENT OF PELLET

In patients the mean water content of the pellet was $73.3 \%$ (range $68-79 \%$ ). This compares with normals in whom the water content was $73.5 \%$ (range $53-81 \%$ ).
PERIODICITY OF FAECAL BILE ACID

EXCRETION AND FAECAL WEIGHT

Figure 2 shows the stool weight, percentage supernatant, total faecal bile acids, and bile acid concentration in the supernatant throughout the day. It would appear that stool weight and total bile acids decrease through the day, but that the percentage supernatant and bile acid concentration in the supernatant does not change. It should be noted that the concentration of bile acids in the supernatant in $50 \%$ of the samples is $>4 \mathrm{mM}$, ie, a concentration observed in the duodenum.

\section{Discussion}

Stool consists of unabsorbed vegetable fibre, bacteria, water, organic, and inorganic substances. The unabsorbed vegetable fibre in the stool holds water, some of which is adsorbed to the surface of the fibre (water of hydration). The remainder is trapped in the interstices of the fibre (bulk water). The capacity to hold water is influenced by the chemistry of both the fibre and the liquid phase (Jirgensons and Straumanis, 1962). In the diarrhoeal stool the capacity to hold interstitial water is exceeded and a liquid stool ensues.

In this study we have endeavoured to separate the diarrhoeal stool into solid and liquid phases and to explore the distribution of bile acids in each phase. We have used $14000 \mathrm{~g}$ for one hour at $10^{\circ} \mathrm{C}$, this being the speed at which the normal stool yields no supernatant but is fast enough to give a good separation of a diarrhoeal stool into supernatant and pellet. This clear distinction between the normal and diarrhoeal stool cannot be achieved if one uses speeds of $100000 \mathrm{~g}$ as used by other workers (Kern, personal communication; Hofmann and Poley, 1972). Centrifugation at $14000 \mathrm{~g}$ for one hour gives a clear separation that is very little improved upon even if centrifugation is continued for as long as eight hours $(2 \%$ more supernatant after eight hours compared with one hour).

Stool is probably a complex colloidal system with 
consequent limits in stability. Therefore freezing the stool at $-20^{\circ} \mathrm{C}$ and at a later stage warming to $10^{\circ} \mathrm{C}$ could affect the adsorbed, interstitial, and free water compartments. It is therefore important to compare the frozen and later thawed diarrhoeal stool with fresh stool and to look at the bile acid distribution between the supernatant and pellet after centrifugation. This possible source of error was not, however, confirmed.

It is important that the spinning technique should yield a pellet that does not have a greater water content than normal stool, the normal stool, according to our observations, being $100 \%$ pellet. The pellets obtained from the diarrhoeal stools contained $73.3 \%$ water and the stools from normal subjects $73.5 \%$ water. These data were obtained by freeze drying the pellets. The supernatant, therefore, accurately reflects the additional fluid component which has caused the stool to be liquid. The findings that the concentration of sodium and potassium in the supernatant was the same as that in the pellet suggests that the water in the pellet is in equilibrium with that of the supernatant. This method does not enable us to say how the diarrhoeal stool has exceeded its capacity to bind water. It could be that there is insufficient fibre to absorb excess water, this excess water resulting from inhibition of sodium and water reabsorption in the colon by, for example bile acids (Forth, Rummel, and Glasner, 1966; Mekhjian, Phillips, and Hofmann, 1971). Alternatively the high concentrations of bile acids may interfere with the water-holding capacity of the fibre.

The highly significant difference in the pellet bile acid content between patients and controls (mean bile acid content $\mathrm{mg} / \mathrm{g}$ freeze dried faeces patients = 55.8 , controls $=8.3, \mathrm{P}<0.005)$ demonstrates the considerable reserve ability of dietary residue to ‘bind' bile acids. It could be that in these patients this binding capacity reaches saturation and therefore causes a certain proportion of the faecal bile acids to be present in solution. This saturation phenomenon is currently being investigated.

Using this method we have investigated the periodicity of faecal bile acid excretion through 24-hour cycles of up to five days. Although faecal weight and total bile acid excretion decreased throughout the day, the percentage of supernatant and bile acid concentration were unchanged. A decrease of bile acids throughout the day has been observed in the proximal small bowel of patients with ileal resection (Van Deest, Fordtran, Morawski, and Wilson, 1968). We were unable to establish a relationship between the faecal bile acid excretion, the Schilling test result, or the faecal fat excretion per 24 hours.

The centrifugation method we have described lays the foundation for this and future studies in establishing whether it is the bile acids in the pellet, in the supernatant, or a combination of both that causes a response leading to the distressing diarrhoea in this unfortunate group of patients.

We are grateful to Dr Horn and the staff of the Clinical Chemistry Department, Western General Hospital, for faecal fat and electrolyte analysis and Dr N. Allan for Schilling tests. We would also like to thank Miss Rhoda Anderson for her skilled assistance, Drs W. Sircus and J. P. A. McManus for access to patients in their care, and Mrs Anne Jenkinson for her secretarial help.

\section{References}

Evrard, E., and Janssen, G. (1968). Gas liquid chromatographic determination of human fecal bile acids. J. Lipid Res., 9, 226-236.

Forth, W., Rummel, W., and Glasner, H. (1966). Zur resorptionshemmenden Wirkung von Gallensäuren. Naunyn-Schmiedebergs. Arch. Pharmak. exp. Path., 254, 364-380.

Hinton, J. M., Lennard-Jones, J. E., and Young, A. C. (1969). A new method for studying gut transit times using radioopaque markers. Gut, 10, 842-847.

Hofmann, A. F., and Poley, J. R. (1969). Cholestyramine treatment of diarrhea associated with ileal resection. New Engl. J. Med., 281, 397-402.

Hofmann, A. F., and Poley, J. R. (1972). Role of bile acid malabsorption in pathogenesis of diarrhoea and steatorrhea in patients with ileal resection. Gastroenterology, 62, 918-934.

Jirgensons, B., and Straumanis, M. E. (1962). A Short Text Book of Colloid Chemistry, 2nd ed. Pergamon Press, Oxford.

Mekhjian, H. S., Phillips, S. F., and Hofmann, A. F. (1971). Colonic secretion of water and electrolytes induced by bile acids: perfusion studies in man. J. cl in. Invest., 50, 1569-1577.

Norman, A. (1964). Faecal excretion products of cholic acid in man. Brit. J. Nutr., 18, 173-186.

Van Deest, B. W., Fordtran, J. S., Morawski, S. G., and Wilson, J. D. (1968). Bile salt and micellar fat concentration in proximal small bowel contents of ileectomy patients. J. clin. Invest., 47, 1314-1324.

Varley, H. (1962a). Practical Clinical Biochemistry, 3rd ed., p. 118. Heinemann, London.

Varley, H. (1962b). Practical Clinical Biochemistry, 3rd ed., p. 346. Heinemann, London.

Woodbury, J. F., and Kern, F., Jr. (1971). Fecal excretion of bile acids : a new technique for studying bile acid kinetics in patients with ileal resection. J. clin. Invest., 50, 2531-2540. 